\title{
The effects of household assets inequality and conflict on population health in Sudan
}

\author{
Amel S. Omer ${ }^{1}$, Stephen Bezruchka ${ }^{2}$, Dario Longhi ${ }^{3}$, Zane Kelly ${ }^{4}$, Marsha Brown ${ }^{5}$ and \\ Amy Hagopian ${ }^{6}$ \\ ${ }^{1}$ Sudan Federal Ministry of Health, Khartoum, Sudan. amlna77@yahoo.co.uk
}

${ }^{2}$ Departments of Health Services and Global Health, University of Washington, Seattle, Washington, USA.sabez@uw.edu

${ }^{3}$ Participatory Research Consulting LLC, Olympia, Washington, USA. dario.marsha@comcast.net

${ }^{4}$ University of Washington Applied Physics Lab, Seattle, Washington, USA. zanemk@gmail.com

${ }^{5}$ Participatory Research Consulting LLC, Olympia, Washington, USA. Marsha.Brown@seattlecolleges.edu

${ }^{6}$ Departments of Health Services and Global Health, University of Washington, Seattle, Washington, USA. hagopian@uw.edu

\begin{abstract}
We explored the effects on health of both household asset inequality and political armed conflict in Sudan. Using the 2010 Sudan household survey, we evaluated the role of both household asset distribution (measured by the Gini coefficient) and armed conflict status at the state level. We measured associations with six health-related outcomes: life expectancy, infant mortality, height-for-age (stunting), adequacy of food consumption, teenage birth rates and vaccination coverage for young children. For each of six measures of health in Sudan, outcomes were significantly worse in the states with more unequal asset distribution, with correlation coefficients ranging between -0.56 (stunting) and -0.80 (life expectancy). Conflict status predicted worse outcomes. Wealth redistribution in the more unequal states, as well as a political resolution of conflict, may improve population health
\end{abstract}

Keywords: Africa; Sudan; Health inequalities; Income inequality; Poverty

\section{Résumé}

Nous avons essayé de comprendre les effets des inégalités de la maisonneé qualité et du conflit armé au Soudan sur la santé. En se basant sur le sondage national Soudanais effectué en 2010, nous avons évalué le rôle de la répartition inégalités de patrimoine (mesurée par le coefficient de Gini) et du conflit armé au niveau de l'état. Nous avons mesuré les associations avec six indicateurs de la santé : l'espérance de vie, la mortalité infantile, la taille par rapport à l'âge (retard de croissance), la suffisance en matière de nutrition, taux de fécondité adolescente et taux de vaccination chez les enfants. Pour chacune des six mesures de santé au Soudan, les résultats étaient significativement pires dans les états ayant une répartition inégale des revenus, avec des coefficients de corrélation variant entre -0.56 (retard de croissance) et -0.80 (espérance de vie). L'état de conflit était un indicateur de résultats négatifs. La redistribution des richesses vers les états ayant une inégalité plus grande, ainsi que la résolution politique du conflit armé, pourraient contribuer à l'amélioration de la santé de la population.

Mots clé: Afrique; Soudan; Les inégalités de santé; L'inégalité des revenus; pauvreté 


\section{Introduction}

The authors hypothesize a relationship between household assets inequality, conflict and poor health outcomes in Sudan. Sudan's 31 million people represent diverse cultures, both Arabic and African. Sudan is a poor country, with a Human Development index of 0.41 , ranking $17 /$ st of 187 countries. The country has suffered political instability since independence from Britain in 1956, with two revolutions and a 40-year civil war. Armed conflict in western Sudan and states bordering South Sudan is ongoing (Central Intelligence Agency 20 I3).

\section{Literature review and theoretical framework}

Inequality affects the health of millions of people globally, in both developed and developing countries. Inequality has been linked to physical and mental health problems, as well as broad social problems such as violence and crime (Wilkinson and Pickett 2009).

The relationship between inequality and poor health captured researchers' interest decades ago. Rodgers studied income inequality as a determinant of health in 1979, concluding countries with more equal income distribution patterns enjoyed higher overall life expectancy (Rodgers 1979). The average difference in life expectancy between more equal countries and less equal countries was as much as five to ten years. Population health metrics, such as mortality, have been linked to social cohesion, trust and community support (Arden, Sen et al. 1996; Sen 2000).

Current researchers have built on this early work. Wilkinson and Pickett wrote a book in 2009 arguing that gross inequality undermines national life, decreases trust, and generates a higher prevalence of frustration, depression and crime (Wilkinson and Pickett 2009). Persons living in unequal societies or countries are inhibited from achieving their personal potential, which collectively inhibits their country's development and growth. Inequality also passes on health effects from one generation to the next; new generations can inherit poor health from previous generations who lived decades ago. Emanuel et al. studied the relationship between grand-maternal and maternal factors in relation to maternal adult stature. Mother's stature was predicted partially by her own mother's stature, and partly by her birth weight. The study concludes, "some birth outcomes are already established before a prospective mother is conceived or born." (Emanuel, Kimpo et al. 2004).
Some researchers argue that even high levels of personal wealth and income do not protect the rich living in unequal societies. Biggs et al researched the effects of inequality and poverty on public health in low, middle, and high-income countries. They studied 22 countries in Latin America between 1960 and 2007, finding that while an increase in national gross domestic product (GDP) had a positive effect on population health, it was not sufficient to counter the effects of inequality and widespread poverty. With rising inequality, GDP had only modest effects on life expectancy and infant mortality rates. However, GDP had a large effect on population health when inequality was reduced. The authors concluded, "wealthier is indeed healthier, but how much healthier depends on how the increases in wealth are distributed." (Biggs, King et al. 20I0).

Similarly, Pop et al. studied income inequality in relation to economic growth. Researchers studied life expectancy in I40 countries between 1987 and 2008. The study showed countries with higher levels of income inequality have lower levels of life expectancy in both low and middle-income countries. In high-income countries, the relationship was not significant. Authors suggest economic growth has a weaker benefit for population health in highly developed countries (Pop, Ingen et al. 2013).

The relationship between income and health is harder to study in low and middle-income countries, where measures of income are more difficult to approximate. Nowatzki studied the relationship between wealth inequality (rather than income inequality) and population health in 14 wealthy countries. She was able to use a wealth indicator in place of measures of monetary income, but still used the traditional "Gini coefficient," a measure of statistical dispersion of monetary income developed by the Italian statistician, Corrado Gini. Nowatzki confirmed wealth inequality was associated with life expectancy and infant mortality, and argued that relying on income instead of wealth is inadequate for addressing economic and health circumstances of individual and families in lower-income countries (Nowatzki 20I2).

Rasella et al. studied income inequality on life expectancy in a highly unequal, but rapidly changing, developing country, Brazil (2000 to 2009). Authors concluded reducing income inequality in developing countries should be a first step towards increasing life expectancy (Rasella, Aquino et al. 2013). Olson et al. found a relationship between inequality and infant mortality rate in the US, highlighting the importance of the first I,000 days of life and their 
effects on adult health (Olson, Diekema et al. 20I0). In the Philippines, Kraft et al. showed wealth equitymarkers were evident in relation to child mortality, and recent wealth-related inequalities were found to be strongly associated with many social factors (Kraft, Nguyen et al. 2013). Another study in Ghana showed a strong association between childhood under-nutrition and inequality (Hong 2007).

In this study we tested the relationship between household assets inequality, conflict and various indicators of poor population health including life expectancy and infant mortality, and also "stunting," adequacy of food consumption, teenage births and vaccination coverage. "Stunting," a lower than expected body height for age, reflects childhood food insecurity and untreated infection. Elshibly and Schmalisch found a significant association between maternal body mass and newborn birth weight in Sudan (Elshibly and Schmalisch 2009). Growth failure is often used to measure the effects of health policies and health planning interventions over the long term.

Higher teenage pregnancy rates, which put infants at risk of poor health outcomes, have been associated with income inequality by previous research (Gold, Connell et al. 2004; Pickett, Mookherjee et al. 2005; Wilkinson and Pickett 2006)

Vaccinations can often prevent physical diseases that lead to higher infant mortality and poor physical development. Vaccine coverage has not necessarily been associated with inequality (Nagaoka, Fujiwara et al. 2012), but we tested this relationship, especially in the context of conflict-involved states.

The relationship between income inequality and armed conflict is contested and complicated. Recent research suggests that while simple inequality between rich and poor may not be enough to lead to civil war, what is potentially explosive is "horizontal conflict," that is, the interaction between inequality and other group identity, such as race, religion or language $(\varnothing$ stby 2008). This may be particularly pertinent in Sudan, where race and religious differences are perceived as large and political struggles have been endemic.

In the western Darfur region, a conflict has raged since 2003 in three states, leading to the displacement of more than two million people and the killing of an estimated 400,000 (CIA 20I3). At the end of 2004, North and South Sudan signed a peace agreement (United Nations Missions December 3I, 2004), which eventually led to South Sudan separating from the federal republic. In July, $20 \mathrm{II}$ after a referendum took place and $98.8 \%$ voted for independence, Sudan's ten southern states became part of a new independent country (The Carter Center undated).

This study focuses on the North Sudan states, where one state, the Blue Nile and three Darfur states were torn by conflict before this study's survey was conducted in 2010. Not long after independence, in $20 \mathrm{I}$, conflict commenced again between the two countries over oil rights, involving more border states than the ones identified by this study (Peace Direct 20I I).

Sudan has had difficulty improving population health. The annual rate of reduction in under-five mortality rate in Sudan for the recent 20-year period was only $1.7 \%$, a rate not on track to meet the Millennium Developmental Goals. Infant mortality in Sudan was reduced from 77 to 57 per 1000 live births in the same period (You, New et al. 20I2), a number that is still unacceptably high. Sudan lags behind on Millennium Development Goals, with a prevalence of malnutrition at 32\% (United Nations Human Development Program: Sudan 20I2).

To summarize, our study uses measures of household assets (deemed more appropriate in low income countries than income differences) to investigate the relationship between inequality and poor health outcomes in a single low-income, conflict-affected country.

\section{Data and Methods}

We analyzed the relationship between household assets inequality, conflict and health outcomes in Northern Sudan, using data from Sudan's recentlyreleased cross-sectional household health survey for most of our health outcomes, as well as for our measures of household assets and their unequal distribution. We used census data for measures of mortality rates.

\section{Data Sources}

\section{Sudan Household Health Survey-2}

Data from the SHHS2, essentially equivalent to the internationally-known Demographic and Health Surveys (DHS), were released in early 2013. Carried out between March and May 2010, the survey was conducted by the Federal Ministry of Health and the Central Bureau of Statistics (CBS). The effort was supported by Sudan's Government of National Unity's Ministry of Health and the Southern Sudan Commission for Census, Statistics and Evaluation. Financial and technical support to the SHHS2 were provided by the United Nations Children's Fund 
(UNICEF), the World Health Organization (WHO), U.S. and Japanese aid agencies, and several other United Nations agencies.

The SHHS2 was intended to generate representative data at the national and state levels on population and health indicators, with an emphasis on child and maternal health outcomes. While basic demographic information on all household members was gathered, supplemental surveys obtained additional information about children aged 0 to 59 months and adults aged 15 to 49 years (with separate questions for women and men) (Federal Ministry of Health: Sudan 20I0).

A two-stage cluster sampling design was employed to draw the sample in each state. Using traditional sample size calculations, it was determined 863 households per state would be representative at the $\mathrm{p}<.05$ level. Survey conductors therefore sampled I,000 households in each state, structured as 40 clusters from each state, and 25 households in each cluster. Clusters were selected with probability proportional to the population size, and with urban and rural stratification. In cases where selected villages were not accessible for security or other problems, they were replaced by neighboring ones in the sampling frame. Each state sample was weighed so that collectively they are representative of the entire national population (Federal Ministry of Health: Sudan 2010). A total of 240 interviewers and 60 supervisors were trained to collect data, and average field time (per state) was 33 days (Federal Ministry of Health: Sudan 20 I0). Five questionnaires were used for each household: I) household characteristics, 2) individual women (age 15-49), 3) children under five, 4) men (age 15-49) and 5) food security (Federal Ministry of Health: Sudan 20I0).

Of the 15,000 households selected for the sample, 14,921 were occupied, and 14,778 were successfully interviewed (response rate 99\%). In those households interviewed, 18,614 women (aged $15-49$ years) were identified, and $92 \%(17,174)$ were interviewed. In addition, 13,587 children under age five were found, and data were collected on $98 \%$ of these. Although 16,448 men were identified, only 5,573 men could be interviewed (34\% response rate). Because of the low response rate, and likely resulting bias, data relating to men are not presented. Rural areas showed higher response rates than urban areas (Federal Ministry of Health: Sudan 2010).

\section{Census}

The second source of data used was Sudan's fifth population and housing census, generated from the long-form questionnaire of the 2008 population and housing census covering social, economic, demographic and housing characteristics, household ownership of durable goods, agricultural lands, livestock, and sources of livelihood of the household. The Census was conducted by the Ministry of the Cabinet and Central Bureau of Statistics, and serves the nation by providing population count and economic development indicators for planning, monitoring and evaluation purposes (Sudan Central Bureau of Statistics 2010). The census was conducted according to United Nation standards, guaranteeing full coverage and high accuracy. The de facto method was applied for the enumeration of the population, the "quick count" methodology for mapping purposes, and detailed questionnaires followed UN principles and recommendations for censuses. Data collectors were teachers from the enumeration areas where they worked, supplemented by qualified persons from the same tribes.

\section{Measures of household assets and inequality}

The SHHS2 surveyed the assets of all households. Factor analysis weights of these assets were used to construct a "household assets score" to approximate the standard of living of each household (O'Donnell, van Doorslaer et al. 2008). The survey identified two kinds of assets: durable goods and housing characteristics. Durable goods elements included such items as animal drawn cart, bicycle, motorcycle, car, sewing machine, refrigerator, radio, TV, clock, fan, land or mobile phone, farmland and animals. Housing characteristics included type of floor and roof, type of drinking water and sanitation, and type of cooking and lighting fuel. The household asset indicator was constructed by (I) statistically calculating the weights of all these assets on a common dimension, a principal component factor, (2) adding the weights of all these assets for each household and generating a statewide asset average for all households, and, finally, (3) creating a standard deviation score for each household from the statewide average.

In countries like Sudan, where the population derives a livelihood from varying types of production (including subsistence agricultural production) and varying forms of exchanges, household asset scores (derived from careful surveys) may be a more reliable indicator of living standards than reports of 
income or consumption (Hahn, Puffer et al. 2005). A similar study in Colombia, another lower-middle income country like Sudan, used a similar household assets indicator as a determinant of socioeconomic inequality for contraceptive use (Gonzalez, Houweling et al. 2010).

The degree of inequality in household assets across a population is an indicator of inequality in living standards, as is the degree of income inequality. The literature on the relationship between inequality and health has traditionally used the "Gini coefficient" to characterize distributions of income. The Gini is a summary statistic of the Lorenz curve, which, in the case of income, plots what proportion of total income was earned by what proportion of the population. More precisely, it is the plot of the proportions of total national income earned by each cumulative proportion of the population, arranged from lower to higher earners. A Gini coefficient of zero expresses perfect equality (everyone has an exactly equal income), and a value of I expresses maximal inequality (where only one person has all the income). In wealthy countries, the Gini coefficient based on monetary income is used to indicate the degree of inequality in standard of living. In developing countries, where many people engage in subsistence agriculture and informal employment and exchange, the inequality in the distribution of household assets is typically a better measure of inequality in living standards. As the poorest in developed countries are those who earn close to no monthly income, so the poorest in more developing countries are those who have close to no household assets (shelter, running water, septic system, readily available energy, means of transportation or communication). The richest households have all of those features, and they are more accessible, functional and elaborate.

\section{Measures of health}

\section{Life expectancy}

Life expectancy was calculated at the state level by the CBS using Census data. It is simply the average number of years a newborn can expect to live given current mortality rates, based on national average life tables (Sudan Central Bureau of Statistics 2010).

\section{Infant Mortality Rate (IMR); Source (Census)}

Sudan's infant mortality rate was derived from Census data by the CBS. The probability of a child dying before its first birthday was calculated by dividing the number of live births in 2008 by the number of children who died that year (Sudan
Central Bureau of Statistics 2010). We elected to use Census data for this calculation, rather than SHHS2 data, believing Census data to be more complete (Federal Ministry of Health: Sudan 20 I0).

\section{Height for age}

A standard international approach to measuring nutritional adequacy is to assess the proportion of the child population that endures "stunting," defined by UNICEF as inadequate height for age (measured as lower than two standard deviations from median height for age compared to a reference population). Height-for-age reflects chronic malnutrition, as failure to receive adequate nutrition over time results in recurrent infections that impair the body's ability to absorb or assimilate food (O'Donnell, van Doorslaer et al. 2008). SHHS2 surveyors measured children's heights in each household and collected their age information (Federal Ministry of Health: Sudan 2010).

\section{Food consumption}

A household "food consumption score" was available in the SHHS2, calculated by examining the number of times certain foods were eaten in the seven days preceding the survey, weighted by approximate nutrient density values. The food categories were fruits and vegetables (weighted as I), cereals and tubers (weighted as 2); beans, seeds and nuts (weighted as 3); meat and dairy (weighted as 4); and oils, fats and sugar (weighted as 0.5 ). The food consumption score was calculated by adding all the results of the individual calculations and then multiplying the frequency of consumption by the score of food type. The number of times any particular item was eaten was capped at 7 per week. Household food consumption scores ranged up to 112. Households were then categorized as having poor, borderline, or adequate levels of food consumption (below 21,21 to 35 , and more than $35)$.

\section{Teen births}

The SHHS2 data contained a measure of women in each household, aged 15-19, who reported they gave birth before age 15 .

\section{Vaccination}

Vaccination data were obtained from the SHHS2, and measured by either the provision of a vaccine card or the mother's recall. Children in each household (between age 12 and 23 months) were assessed to determine whether they were fully immunized according to the national guidelines by 
their first birthday. The vaccine schedule included protection from polio, tuberculosis, diphtheria, tetanus, pertussis, hepatitis $B$, mumps and measles.

\section{Confounders, effect modifiers and possible biases}

The effects of household asset inequality on health outcomes could be modified by the rural/urban status of households, as well as the location of the household in a conflict zone. Rural communities may have more social cohesion, but are also more distant from health services and opportunities for employment (Wilkinson and Pickett 2009). While there are more deaths and injuries as a result of conflict, conflict regions also capture political interest. This attention can generate interventions that alter the natural distribution of human behaviors, health outcomes and resources, especially in relation to nutrition and vaccination (Biggs, King et al. 2010). We analyzed our results both with and without the four conflict states, which are North Darfur, West Darfur, South Darfur and Blue Nile.

Although the survey has a high response rate from households visited, the decision to avoid sampling households in conflict zones was a source of possible bias. Further, all cluster studies suffer from sampling errors in populations that are not evenly distributed according to the characteristics of interest. Population enclaves can readily be missed (Hahn, Puffer et al. 2005). Cluster sampling can substantially increase standard errors (O'Donnell, van Doorslaer et al. 2008). Recall bias is another source of possible error, as not everyone can readily recall meal consumption, vaccination history, and other life events. Another source of bias stems from the time of day or day of week the house was visited (because of who was home to report then).

\section{Data analysis}

We used the statistical program " $R$ " (a GNU free software project, http://www.r-project.org) to calculate Gini coefficients following the specification of two vectors:

$$
\text { Gini }(x, \text { weights }=\text { rep }(\text { l length }=\text { length }(x)))
$$

where the first vector, $\mathrm{x}$, is the $\mathrm{z}$-score value of assets for each household, and where the second vector, weights, is the sampling weight for $\mathrm{x}$. This second vector was necessary to calculate the Gini for Sudan as a whole since the survey sampling was a complex one, divided into various strata and clusters.

We converted the original SHHS2 household asset scale (which provided household scores that ranged between -3 standard deviations and +3 standard deviations) to a scale with all positive values (required for calculating the Gini coefficients), varying from 0 to 5.25 . To do this, we converted the minimum value to 0 and added the same constant to all scores.

As a check on the validity of our methods, we calculated the correlation between Gini coefficients and skewness coefficients for each of the 15 states. Skewness is another measure of inequality based on the distributions of assets across households in each state. The skewness coefficient is high if the distribution is not "normal" - with many households having "middle level assets," but skewed, with very many households having few assets. The high correlation (at 0.89 ) between the two measures of inequality, Gini and Skewness, increased our confidence in the inequality values used in this study.

\section{Ethical review:}

SHHS2 data collection procedures were approved by Sudan's national institutional review board. The University of Washington Human Subjects Institutional Review Board (IRB) exempts from review those studies based on national level data sets that contain no identifiable information on the subject participants.

\section{Results}

Table (I) shows the populations studied in each of our two data sources, with total population in the census and total households in the SHHS2 survey. We present data on children under five separately, as they are the focus of several of our health measures (infant mortality, stunting, and proportion appropriately vaccinated). The SHHS2 obtained measurements on 13,587 children from 14,778 households in 15 states. Three out of the four states with the largest number of children sampled - those having 1000 or more children in the sample, were all in conflict regions.

Table I: Sizes of populations and sizes of survey samples in each state and Sudan

\begin{tabular}{|c|c|c|}
\hline State & Census data & SHHS samples \\
\hline
\end{tabular}




\begin{tabular}{|c|c|c|c|c|}
\hline & Population & Under- five population & $\begin{array}{c}\text { Sample size } \\
\text { of } \\
\text { children under five }\end{array}$ & $\begin{array}{l}\text { Mother/caretaker } \\
\text { of } \\
\text { children under-five } \\
\text { interviewed }\end{array}$ \\
\hline Northern & 686,098 & 80,344 (II.7\%) & 637 & 607 (95\%) \\
\hline River Nile & $\mathrm{I}, 097,356$ & $145,560 \quad(13.3 \%)$ & 789 & 765 (97\%) \\
\hline Gezira & $3,549,026$ & 511,776 (14.4\%) & 843 & 839 (99\%) \\
\hline Khartoum & $5,181,186$ & $650,463 \quad(12.6 \%)$ & 862 & 828 (96\%) \\
\hline White Nile & $\mathrm{I}, 7 \mathrm{I}, 3,360$ & $267,270 \quad(15.6 \%)$ & 889 & $856(96 \%)$ \\
\hline Sennar & $\mathrm{I}, 272,766$ & $203,041 \quad(16.0 \%)$ & 853 & 843 (99\%) \\
\hline Red Sea & $\mathrm{I}, 368,330$ & $155,127 \quad(11.3 \%)$ & 641 & 625 (97\%) \\
\hline South Kordufan & $1,389,076$ & $260,172 \quad(18.7 \%)$ & $|, 03|$ & $\mathrm{I}, 020 \quad(99 \%)$ \\
\hline Kassala & $\mathrm{I}, 769,887$ & $220,488 \quad(12.5 \%)$ & 824 & 818 (99\%) \\
\hline Gedarif & $\mathrm{I}, 334,947$ & 230,165 (I7.0\%) & 935 & $901 \quad(96 \%)$ \\
\hline North Kurdufan & $2,888,969$ & $494,197 \quad(17.0 \%)$ & 910 & 902 (99\%) \\
\hline North Darfur & $2,089,801$ & $313,592 \quad(15.0 \%)$ & 1,067 & $\mathrm{I}, 034(97 \%)$ \\
\hline Blue Nile & 816,048 & $156,404 \quad(19.0 \%)$ & 1,257 & I,234 (98\%) \\
\hline South Darfur & $4,054,603$ & 625,560 (I5.4\%) & $\mathrm{I}, 074$ & I,034 (96\%) \\
\hline West Darfur & $\mathrm{I}, 292,7 \mid 4$ & $220,946 \quad(17.0 \%)$ & 975 & 967 (99\%) \\
\hline Sudan & $30,504,166$ & $4,535,105$ (15.0\%) & 13,587 & I3,282 (98\%) \\
\hline
\end{tabular}

Sources of data: Sudan Household Survey 2010, conducted between March and May 2010, by the federal Ministry of Health and the Central Bureau of Statistics, and the Sudan Census, generated from the long-form questionnaire of the 2008 population and housing census.

\section{Household Asset Inequality}

We calculated Gini coefficients, measuring the degree of household asset inequality in each state, and provide a bar chart (Figure I) and map (Figure 2) depicting the results.

In Sudan, Northern State was the least unequal state with a Gini coefficient of .206. This indicates a very low level of inequality in household assets (similar to low income Gini scores for Japan and northern European countries like Sweden). We also noted the 637 households in Northern state had a positive average household asset of .88 , with a standard deviation of .77. This indicates that most households in the Northern State were better off than the national average. By contrast, South Darfur State had a Gini coefficient of .536, indicating great inequality (similar to the income inequality levels of countries like Paraguay and Thailand). The average household asset index score of -0.66 , with a standard deviation of 0.65 , shows that most households in South Darfur were poorer in assets than the average household in Sudan. Three of the four conflict states (North, West and South Darfur) were among the top four most unequal states. Table 2 displays the exact Gini coefficients for each state, with an average Gini of .37I for the nation. 


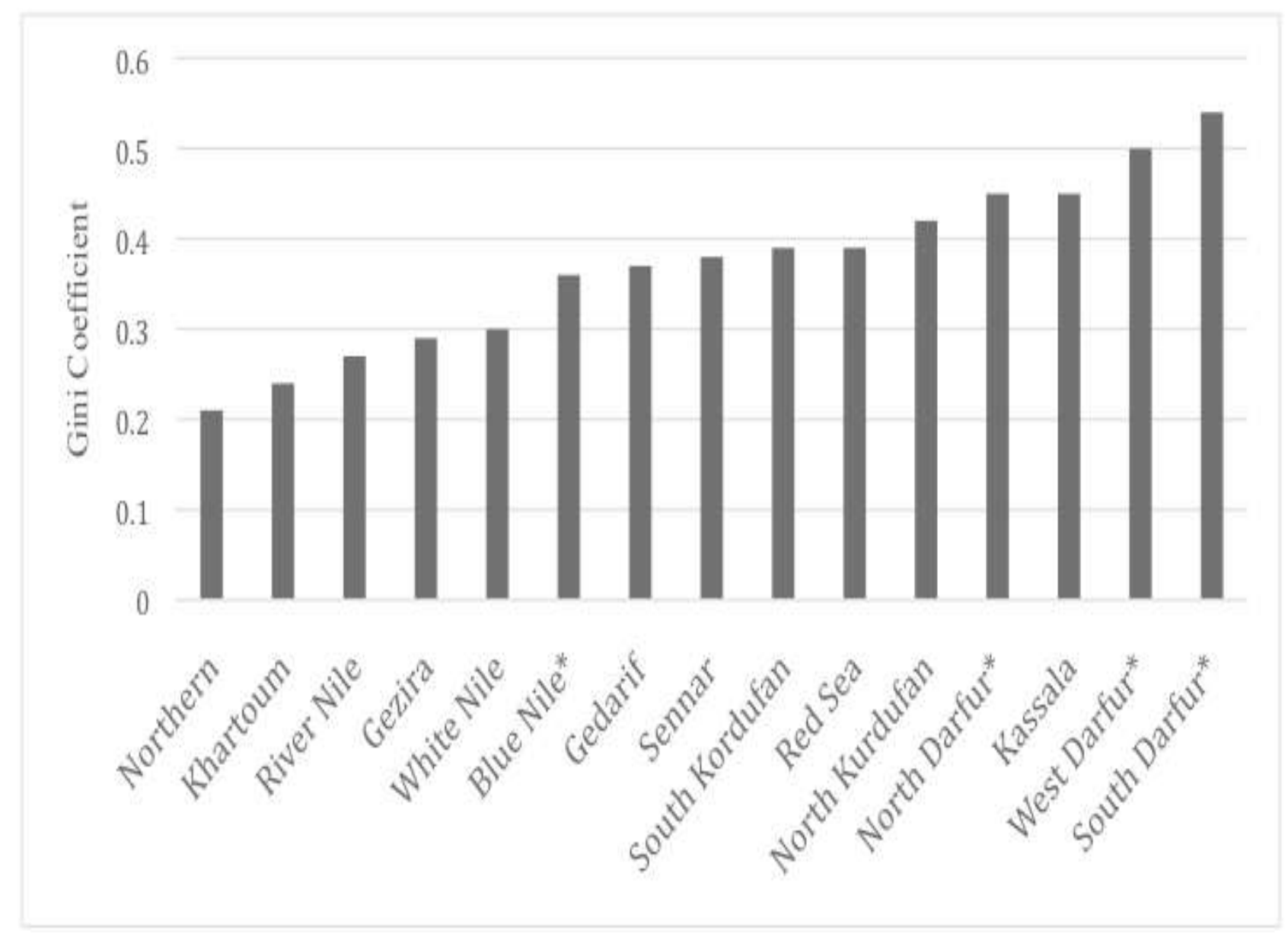

Figure I: Inequality in each state, ordered from lowest to highest inequality.

Source of data: Sudan Household Survey 2010, conducted between March and May 2010, by the federal Ministry of Health and the Central Bureau of Statistics.

The Gini coefficients measure the degree of inequality in household assets in each state.

* West Darfur, South Darfur, North Darfur and Blue Nile are conflict states. 


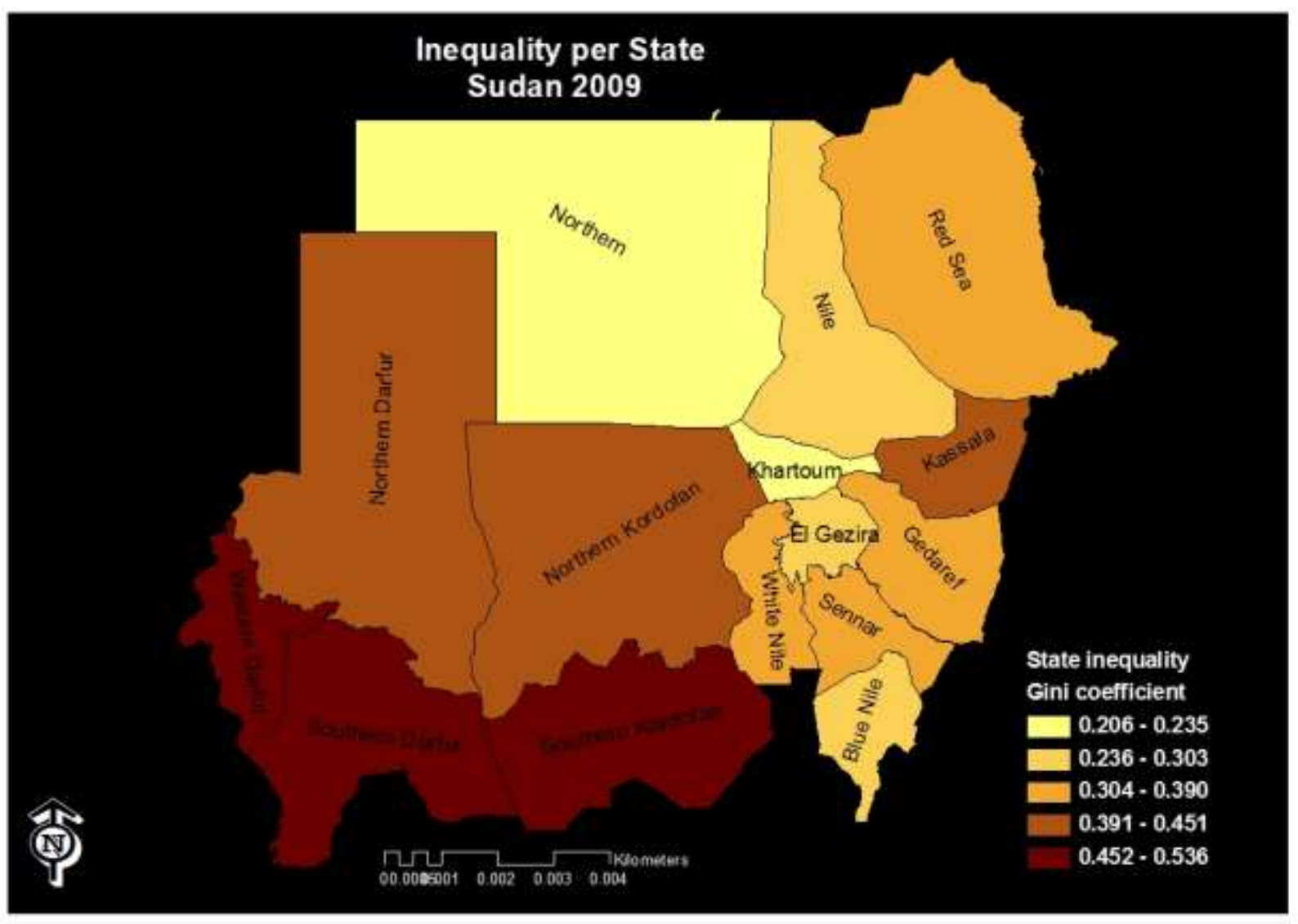

Figure 2: Map of Sudan, showing levels of inequality in each state.

Source of data: Sudan Household Survey 2010, conducted between March and May 2010, by the federal Ministry of Health and the Central Bureau of Statistics.

The Gini coefficients measure the degree of inequality in household assets in each state.

Note: Darker shaded states are the most unequal in household assets. Blue Nile, West Darfur, North Darfur and South Darfur are the conflict states. 
Life expectancy in Sudan was 60 years, with a range of 57 years in West Darfur to 65.5 years in Gezira State. We found that states with more unequal household asset distribution were more

likely to have lower life expectancy. Figure 3a displays life expectancy rates plotted on the $y$-axis and inequality Gini coefficients on the $\mathrm{x}$-axis for each state, The correlation is negative and high: -0.798 : the higher the inequality the lower the life expectancy. The four conflict states (North Darfur, South Darfur, Blue Nile, and West Darfur) had the lowest life expectancies. See Table 2.

Table 2: Degree of inequality and level of health on six health indicators in each state and in Sudan, including correlations between inequality and each health indicator.

\begin{tabular}{|c|c|c|c|c|c|c|c|}
\hline \multirow[b]{2}{*}{ State } & \multirow{2}{*}{$\begin{array}{c}\text { Inequality } \\
\begin{array}{c}\text { Gini } \\
\text { coefficient }\end{array}\end{array}$} & \multicolumn{6}{|c|}{ Health indicators } \\
\hline & & $\begin{array}{c}\text { Life } \\
\text { expectancy } \\
\text { (years) }\end{array}$ & $\begin{array}{l}\text { Infant } \\
\text { mort. } \\
\text { rates } \\
\text { (IMR) }\end{array}$ & $\begin{array}{c}\text { Mean } \\
\text { height } \\
\text { for age } \\
\text { (z score) }\end{array}$ & $\begin{array}{l}\text { Percent with } \\
\text { adequate food } \\
\text { consumption }\end{array}$ & $\begin{array}{c}\text { Percent } \\
\text { teenage } \\
\text { births }\end{array}$ & $\begin{array}{c}\text { Percent } \\
\text { vaccinated }\end{array}$ \\
\hline South Darfur* & 0.536 & 57.6 & 349 & -1.35 & 88.7 & 22.2 & 34.1 \\
\hline West Darfur* & 0.502 & 57.0 & 318 & -1.39 & 76.6 & 30.1 & 38.6 \\
\hline Kassala & 0.451 & 58.7 & 227 & -1.87 & 89.3 & 14.0 & 46.6 \\
\hline North Darfur* & 0.445 & 57.1 & 145 & -1.36 & 80.9 & 15.6 & 43.4 \\
\hline North Kurdufan & 0.422 & 59.0 & 104 & -1.73 & 83.5 & 17.1 & 37.0 \\
\hline Red Sea & 0.390 & 59.0 & 145 & -1.92 & 85.0 & 12.0 & 35.1 \\
\hline South Kordufan & 0.386 & 57.9 & 90 & -1.44 & 83.9 & 18.8 & 42.7 \\
\hline Sennar & 0.383 & 59.0 & 62 & -1.67 & 90.6 & 15.2 & 65.1 \\
\hline Gedarif & 0.365 & 59.8 & 79 & -1.65 & 90.5 & 21.0 & 58.8 \\
\hline Blue Nile* & 0.364 & 57.2 & 336 & -1.48 & 81.8 & 27.7 & 64.7 \\
\hline White Nile & 0.303 & 61.0 & 70 & -1.53 & 95.1 & 18.2 & 54.9 \\
\hline Gezira & 0.287 & 65.5 & 154 & -1.12 & 96.3 & 13.2 & 62.6 \\
\hline River Nile & 0.273 & 61.0 & 42 & -1.19 & 99.1 & 16.5 & 40.0 \\
\hline Khartoum & 0.235 & 62.0 & 170 & -0.95 & 97.0 & 9.5 & 60.9 \\
\hline Northern & 0.206 & 63.3 & 38 & -0.93 & 98.3 & 7.9 & 60.4 \\
\hline $\begin{array}{l}\text { National } \\
\text { Average } \\
\end{array}$ & $0.37 I$ & 59.7 & 155 & -1.44 & 89.1 & 17.3 & 49.7 \\
\hline $\begin{array}{c}\text { Correlation } \\
\text { with } \\
\text { Inequality } \\
\text { (Gini) }\end{array}$ & & -0.79 & 0.61 & -0.56 & -0.77 & 0.58 & -0.61 \\
\hline
\end{tabular}

Sources of data: Sudan Household Survey 2010, conducted between March and May 2010, by the federal Ministry of Health and the Central Bureau of Statistics, and the Sudan Census, generated from the long-form questionnaire of the 2008 population and housing census.

The Gini coefficients measure the degree of inequality in household assets in each state and Sudan as a whole.

*Conflict states.

\section{Infant mortality}

Sudan's infant mortality rate was 79 per 1,000 live births, with a range of 38 per I,000 live births in Northern State to 349 in South Darfur. There were six states with double-digit infant mortality rates, and nine states with triple-digit figures, the latter ranging from 104 to 349 . See Table 2. States with more unequal household asset distributions were more likely to have higher infant mortality rates, with a positive correlation coefficient of 0.614 . Three of the four conflict states (South Darfur, Blue 
Nile, and West Darfur) suffered both the highest infant mortality and had the most inequality in household assets. See Figure 3b.

\section{Height for age (stunting)}

The international World Health Organization (WHO) norms for height-for-age $z$ scores are 1.10 to I.30 (World Health Organization 1997), and this organization has established that scores between -2 and -3 represent "moderate stunting." The mean score for Sudan was - I.44: the majority of children under age five in Sudan showed stunted growth (low height for age in comparison to the WHO reference population). Sudan's scores ranged from -.93 in Northern State to - I.92 in Red Sea.

The correlation coefficient for the association between Gini and stunting was -0.557 , a relatively weak correlation. See Figure 3c. The conflict states had stunting scores in the middle of the distribution of states, unlike other measures of health where the conflict states performed relatively poorly. When we removed these four states from the analysis, we found a strong correlation, -.913 , between stunting and Gini scores in the remaining II states (not illustrated, $p<.00$ ).

\section{Food consumption}

The food consumption situation in Sudan is relatively good. Overall, 89 percent of households in Sudan reported adequate food consumption, with a range between 99 percent in River Nile state and 76.6 percent in West Darfur state. States with higher Gini scores (i.e., more unequal) were more likely to have lower food consumption scores, with a correlation coefficient of $-\mathbf{0 . 7 7 2}$. Three of the four conflict states reported the lowest percentages of households having adequate food consumption (West Darfur, North Darfur and Blue Nile). See Table 2 and Figure $3 \mathrm{~d}$.

\section{Teen births}

The SHHS2 study found ten percent of young women in Sudan were married before age I5. About 16 percent of women aged 15 to 19 years began bearing children before age 15, with a range of 7.9 percent in Northern State to 30 percent in West Darfur. States with more inequality in household assets were somewhat more likely to have higher teenage birth rates, with a correlation coefficient of 0.58. The three conflict states (West Darfur, Blue Nile, and South Darfur) had the highest teenage birth rates, and two of these had the most unequal household asset measures. See Table 2 and Figure $3 e$.

\section{Proportion vaccinated}

Only about half $(49.7 \%)$ the children aged I2-23 months in Sudan had completed the recommended vaccine schedule at the time of the SHHS2 survey, with a range of 34 percent (South Darfur) to 65 percent (Blue Nile). The correlation coefficient between vaccine coverage and Gini was - 0.613. In contrast to findings on other health status measures in this study, Blue Nile, a conflict state, was among the top two performing states on vaccine coverage for children under age two. See Table 2, Figure 3 f.

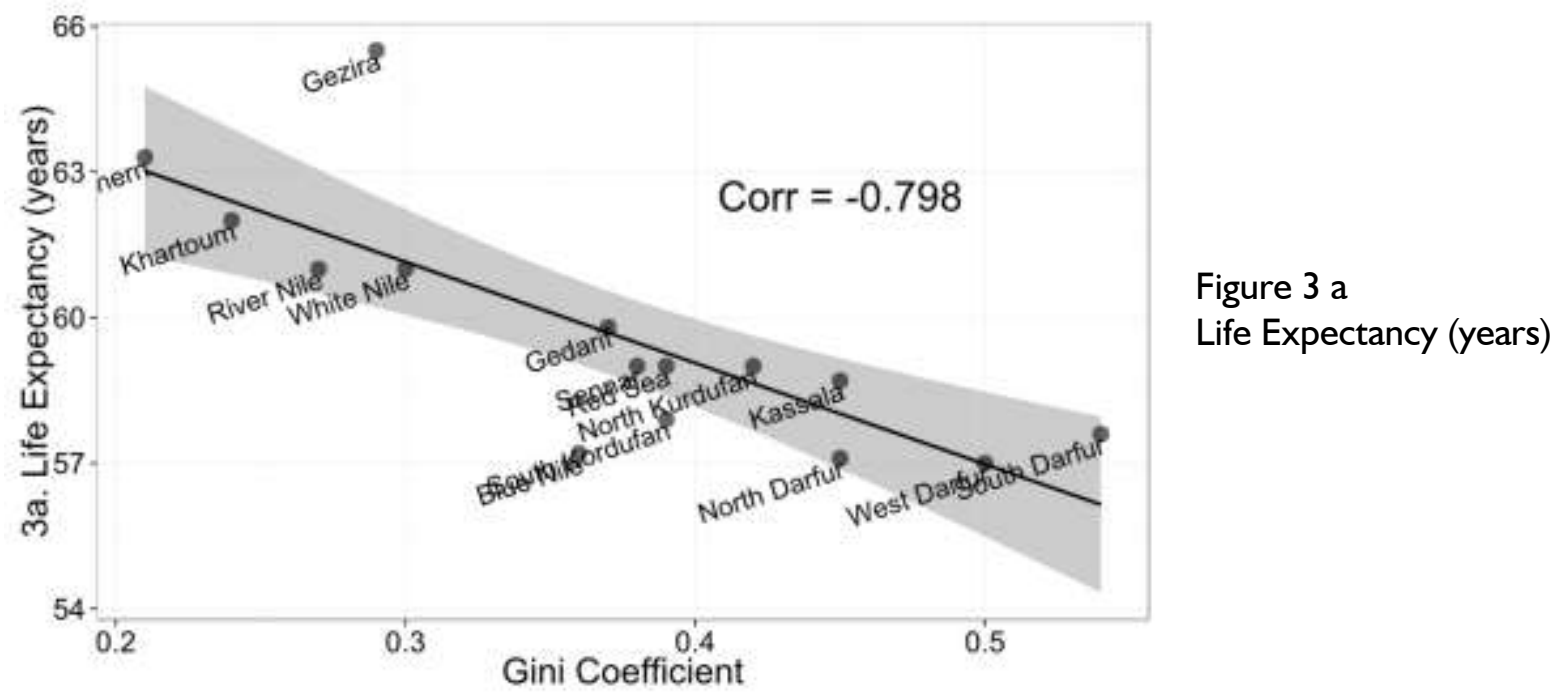



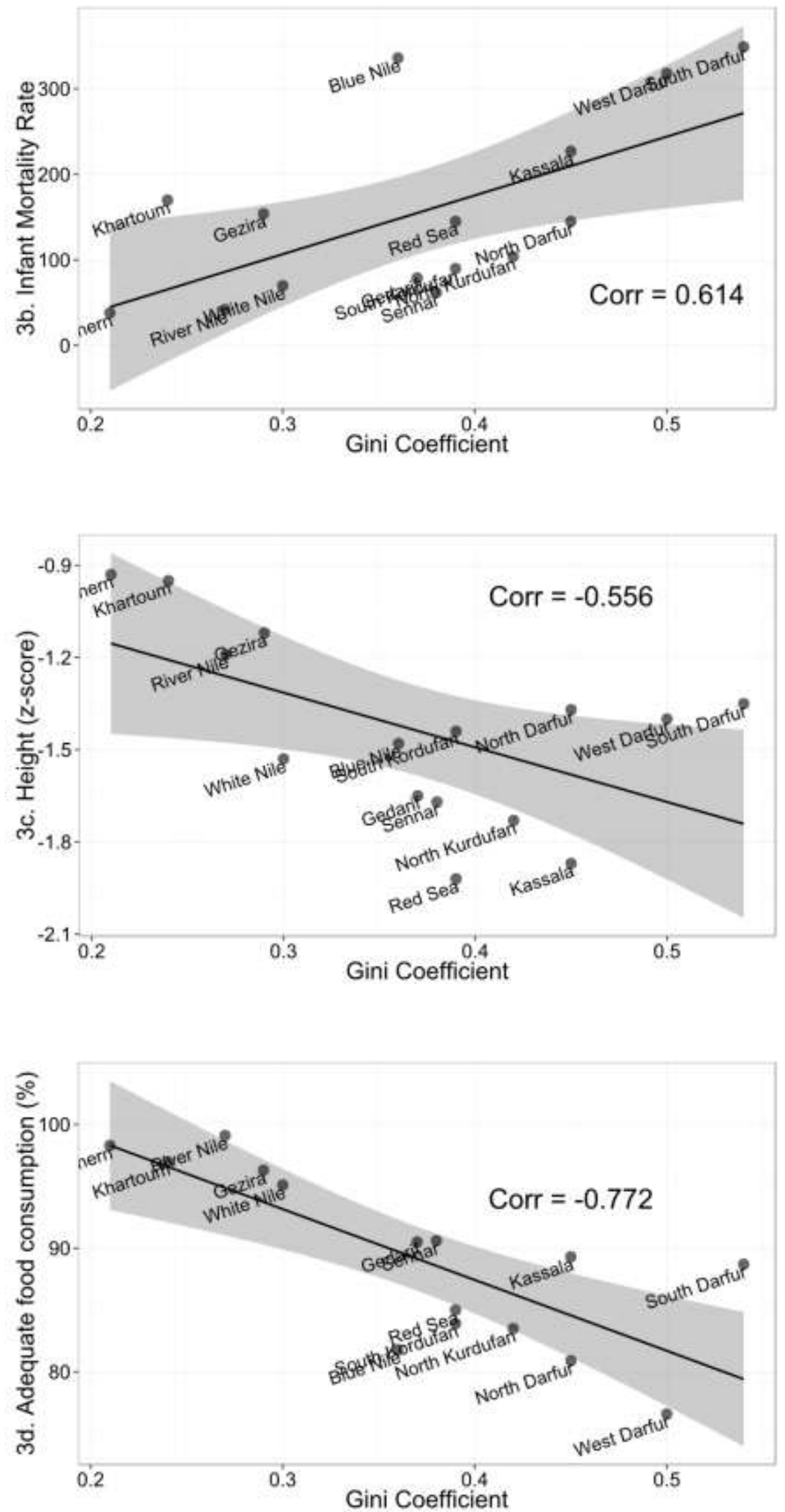

Figure $3 \mathrm{~b}$

Infant Mortality Rate (IMR)
Figure $3 c$

Height for age (z-score)
Figure $3 \mathrm{~d}$

$\%$ with Adequate Food ConsumptionFigure $3 \mathrm{~d}$ 


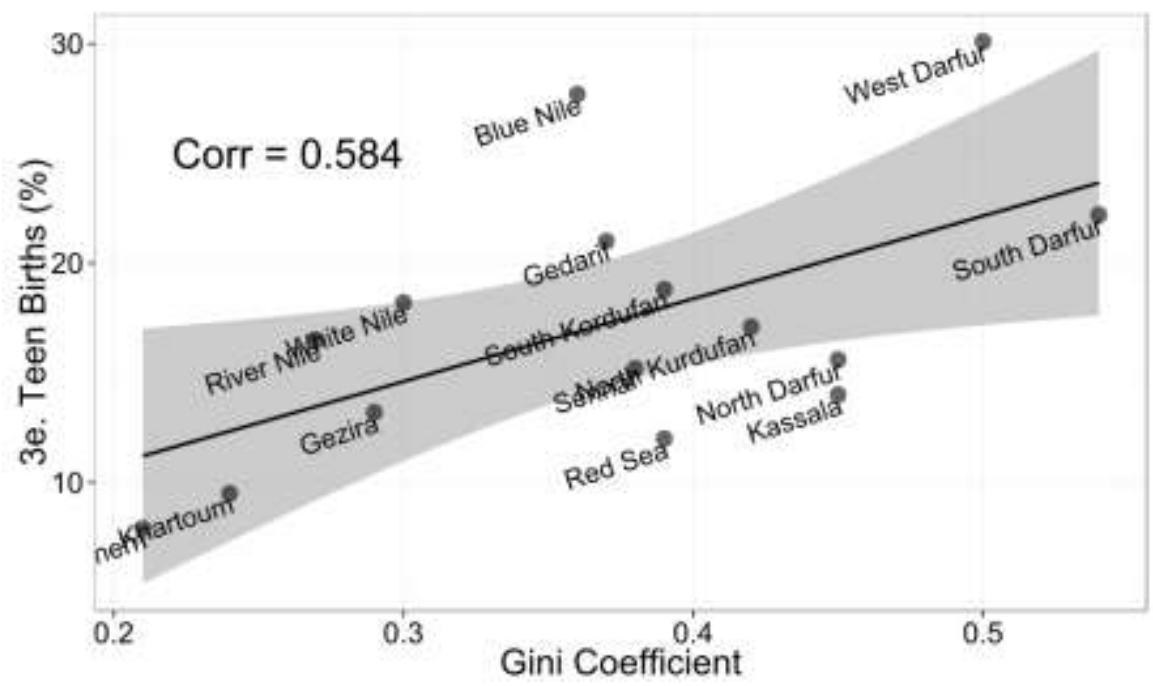

Figure 3 e

$\%$ Teen Births

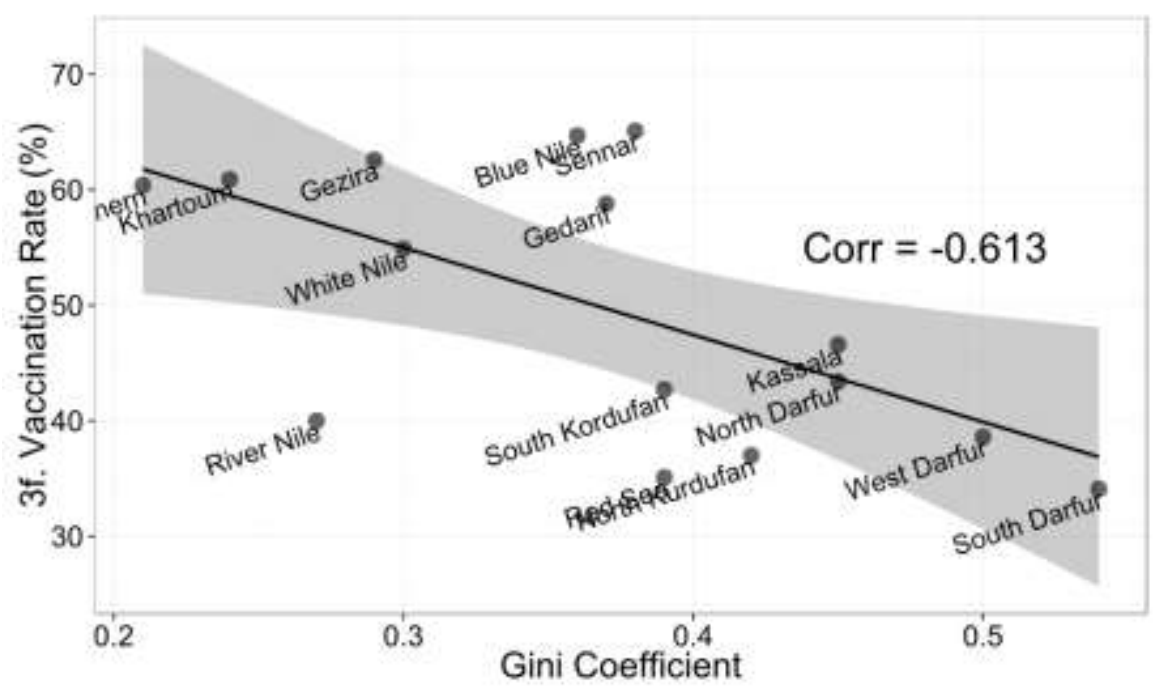

Figure $3 \mathrm{f}$

$\%$ Vaccinated

Figure 3: The effect of differences in inequality on six health indicators: scatter plots, regression lines and correlations.

Sources of data: Sudan Household Survey 2010, conducted between March and May 2010, by the federal Ministry of Health and the Central Bureau of Statistics, and the Sudan Census, generated from the long-form questionnaire of the 2008 population and housing census. The Gini coefficients measure the degree of inequality in household assets in each state

Note: West Darfur, South Darfur, North Darfur and Blue Nile are conflict states.

\section{Discussion}

The object of this study was to test the relationship between inequality and poor health, with an additional aim to observe any interactive effects of conflict.

For each of our six measures of health in Sudan (life expectancy, infant mortality, height-for-age (stunting), food consumption, teen births, and vaccination coverage), worse outcomes were significantly correlated with unequal household asset distributions. Further, the four conflict states typically registered the worst outcomes, although this is compounded in part by having some of the most unequal household asset distributions.

Previously, other authors have reported life expectancy and infant mortality to be associated 
with inequality (Rodgers 1979, Nowatzki 20I2). In relation to food consumption and stunting, a study based on the Nigeria 2003 Demographic and Health Survey found considerable pro-rich inequalities in the distribution of stunting, as well as malnutrition associated with socioeconomic inequality generally (Uthman 2009). Similar findings come from other sub-Saharan countries (Zere and Mclntyre 2003; Van de Poel, Hosseinpoor et al. 2007; Ellen Van de Poel, Ahmad Reza Hosseinpoor et al. 2008; Van de Poel, Hosseinpoor et al. 2008), Vietnam (Wagstaff, van Doorslaer et al. 2003), and China (Chen, Eastwood et al. 2007).

Sudan's Ministry of Health and UN agencies, mainly UNICEF, have focused food supplementation interventions in conflict regions, leading to improvements in height for age in children aged 18 to 24 months. This could explain the lower correlation we found between stunting and household asset distribution ( -0.56 was the lowest correlation score among the six health outcomes). To test the possibility that food supplement interventions in conflict states were masking the effects of inequality we removed conflict states from the analysis. Without the four conflict states, we found a much higher correlation between household asset inequality and stunting $(-0.9 / 3)$. This is consistent with findings from the Biggs paper (Biggs, King et al. 20I0).

We also found higher levels of inadequate food consumption to be associated with higher inequality. This is consistent with studies in other countries demonstrating the relationship between chronic malnutrition in children and income inequality, most recently in Ecuador (Larrea and Kawachi 2005).

Other researchers have found income inequality to be associated with higher birth rates among teens, as we did. A possible explanation is that greater income inequality undermines social capital (social cohesion, civic engagement, and mutual trust in a community). In a U.S. study, teen birth rates were affected by both poverty and income inequality, though income inequality appeared to affect teen birth rates primarily through its effect on social capital (Gold, Kennedy et al. 2002).

The relationship between vaccine coverage and income inequality from other studies is more nuanced. A 2012 study from Japan demonstrated that while higher income inequality was associated with lower measles vaccine coverage rates in more rural areas, larger municipalities could overcome this problem with social capital development (Nagaoka, Fuiiwara et al. 20I2). Conflict areas are the focus of more political interest and health interventions, which may mask some of the effects of inequality. After removing the four conflict states from our analysis of the relationship between inequality and vaccination rates, our correlation coefficient fell from .61 to .48 . The $p$ test value for the latter correlation was not significant. In relation to vaccination during conflict, Parameswaran and Wijesinghe found no differences in vaccination coverage in the war-affected Kilinochchi district of Sri Lanka (Parameswaran and Wijesinghe 20I2), perhaps because vaccine campaigns are typically conducted in war zones by various authorities as a public health measure (Coninx, Dupuy et al. 1998; Gayer, Legros et al. 2007; Parameswaran and Wijesinghe 2012). A measles campaign in camps for internally displaced persons and neighboring communities in Darfur aimed to vaccinate all children aged 9 months- 15 years, and resulted in a reduction in reported measles cases (MMWR 2004). Another confounder could be that higher infant mortality rates in the three conflict states led to the deaths of unvaccinated children, thus artificially elevating the vaccination rate because it was inflated by survivors. Sample bias may also be a problem, because serious security issues forced SHHS2 to replace clusters in war zones with those in safer areas to protect the surveyors.

We conclude from our findings, supported by research from others who have published in this area, that an unequal distribution of household assets, as measured by Gini coefficient based on household assets, is associated with worse health outcomes.

It is possible that the mechanism by which economic inequality undermines health is through the erosion of social capital, since both teen births and vaccine coverage seem to have demonstrated this association. The fact that three of the four conflict states in Sudan have the most household asset inequality supports this hypothesis. On the other hand, the conflict states also share the characteristics of poor infrastructure and rugged geography with few roads. Certain conflict state sites could be inaccessible for months during the rainy season. By comparison, the most equal states are closer to the capital, with good infrastructure, as well as more job and education opportunities. The direction of causality is difficult to differentiate here, as the more equal states have no history of conflict. Is it the inequality that leads to conflict, or the conflict that leads to inequality? 
Racism in Sudan is a significant problem that may also explain some portion of inequality. Northern region people are known to discriminate against those from western Sudan in terms of color and tribal affiliation, which is also reflected in marriage choices (Elkhider 20I2). All these issues relate to social capital, as well.

The effect of conflict on health, regardless of economic inequality, is incontrovertible, however. It has been reported that half a million people may have died in the Darfur conflict, and 2 million people displaced (Biggs, King et al. 2010; Central Intelligence Agency 20 I3).

Our study has limitations. Household assets were estimated by the SHHS2 tallies of cumulative quantity and quality of household assets. While this is a good indicator of living standards, it may not produce the same results as those obtained from direct measures of income. More foundational research is needed on the relationship between household assets, wealth and income inequality in low-income countries.

Cross-sectional data allow calculations of association, but do not provide evidence for causal inferences because of the lack of temporal sequence, among other reasons. Longitudinal research studies are needed on how increases in inequality, in combination with other racial or religious differences, may affect armed conflict, and how both inequality and conflict, independently or together, lead to poorer health.

Vaccine measures and other variables based on respondent recall are subject to bias. The SHHS2 avoidance of surveying in high-conflict zones certainly undermines finding precisely what factors are associated with the effects of conflict. In depth, qualitative, case studies are needed to examine the health effects of inequality and racism in countries, or areas of countries, where conflicts are at least partially based on race and inequality.

\section{Conclusion}

We conclude inequality in household assets is associated with poorer population health in Sudan on six important measures of health: life expectancy, infant mortality, stunting, food consumption, teen births, and vaccination rates. Better health outcomes occurred in the less unequal states. Conflict-zone interventions organized by public health organizations may have masked the extent of the effects of inequality for stunting as well as vaccination coverage. The harms to social capital created by or through both inequality and conflict may be at the root of poor health. Public health officials may want to consider interventions to prevent both war and economic inequality as equally important to other public health interventions.

Living in a more equal society could be the best medicine for a healthier and better life.

\section{Acknowledgments}

Thanks to Dr. Igbal A. Basheer, Sudan Household Survey Executive Director, and Nahid Ali, Survey committee member, who provided the survey data. We appreciate guidance from Nicole Johns at the University of Washington's Institute for Health Metrics and Evaluation. Thanks also to Karin Huster for assistance with the French abstract.

\section{References}

Arden, R., P. Sen, M. Duxbury and Channel Four Films for the Humanities (1996). The great leveller. Princeton, NJ, Films for the Humanities \& Sciences.

Biggs, B., L. King, S. Basu and D. Stuckler (20I0). "Is wealthier always healthier? The impact of national income level, inequality, and poverty on public health in Latin America." Social Science \& Medicine 7 I (2): 266-273.

Central Intelligence Agency. (2013). "World Fact Book." from https://http://www.cia.gov/library/publications/th e-world-factbook/geos/su.html accessed on 2013, May 13..

Chen, Z. A., D. B. Eastwood and S. T. Yen (2007). "A decade's story of childhood malnutrition inequality in China: Where you live does matter." China Economic Review 18(2): I39- I 54.

CIA. (2013). "The World Fact Book." Retrieved May, 13, 2013.

Coninx, R., C. Dupuy, C. Hermann, G. C. Ribeiro, M. Margot and K. Lucic (1998). "Vaccination of the civilian population in a country at war: it can be done; it can also be evaluated. The ICRC experience in Mozambique." $\perp$ Trop Pediatr 44(3): $186-188$.

Elkhider, W. (20/2). Racism in Sudan: A cultural trait. 500 Words Magazine.

Ellen Van de Poel, Ahmad Reza Hosseinpoor, Niko Speybroeck, T. V. Ourti and J. Vega (2008). Socioeconomic inequality in malnutrition in developing countries. Bulletin of the World Health Organization 86(4): 282-29I. 
Elshibly, E. M. and G. Schmalisch (2009). "Relationship between maternal and newborn anthropometric measurements in Sudan." Pediatrics International 5 I (3): 326-33I.

Emanuel, I., C. Kimpo and V. Moceri (2004). "The association of grandmaternal and maternal factors with maternal adult stature." Int. I. Epidemiol. 33(6): I243- 1248.

Federal Ministry of Health: Sudan (2010). Sudan Household Health Survey - Round (2). Khartoum, Federal Ministry of Health.

Gayer, M., D. Legros, P. Formenty and M. A. Connolly (2007). "Conflict and emerging infectious diseases." Emerg Infect Dis I3(II): |625-1631.

Gold, R., F. A. Connell, P. Heagerty, S. Bezruchka, R. Davis and M. L. Cawthon (2004). "Income inequality and pregnancy spacing." Soc Sci Med 59(6): I I I7-II 26.

Gold, R., B. Kennedy, F. Connell and I. Kawachi (2002). "Teen births, income inequality, and social capital: developing an understanding of the causal pathway." Health \& Place 8(2): 77-83.

Gonzalez, C., T. A. Houweling, M. G. Marmot and E. J. Brunner (2010). "Comparison of physical, public and human assets as determinants of socioeconomic inequalities in contraceptive use in Colombia - moving beyond the household wealth index." Int | Equity Health 9: 10.

Hahn, S., S. Puffer, D. J. Torgerson and J. Watson (2005). "Methodological bias in cluster randomised trials." BMC Med Res Methodol 5: 10.

Hong, R. (2007). "Effect of economic inequality on chronic childhood undernutrition in Ghana." Public Health Nutrition I 0(4): 37I-378.

Kraft, A. D., K.-H. Nguyen, E. Jimenez-Soto and A. Hodge (20I3). "Stagnant Neonatal Mortality and Persistent Health Inequality in Middle-Income Countries: A Case Study of the Philippines." PLOS ONE 8(I): e53696.

Larrea, C. and I. Kawachi (2005). "Does economic inequality affect child malnutrition? The case of Ecuador." Social Science \& Medicine 60(I): 165 178.

MMWR (2004). "Emergency measles control activities--Darfur, Sudan, 2004." Morb Mortal Wkly Rep 53(38): 897-899.

Nagaoka, K., T. Fujiwara and J. Ito (20/2). "Do income inequality and social capital associate with measles-containing vaccine coverage rate?" Vaccine 30(52): 748I-7488.
Nowatzki, N. R. (20/2). "Wealth inequality and health: A political economy perspective." International Journal of Health Services 42(3): 403-424.

O'Donnell, O., E. van Doorslaer, A. Wagstaff and M. Lindelow (2008). Analyzing health equity using household survey data : a guide to techniques and their implementation. Washington, D.C., World Bank.

Olson, M. E., D. Diekema, B. A. Elliott and C. M. Renier (2010). "Impact of Income and Income Inequality on Infant Health Outcomes in the United States." Pediatrics I 26(6): I I65- I I 73.

Østby, G. (2008). "Polarization, Horizontal Inequalities andPolarization, Horizontal Inequalities and Violent Civil Conflict." Journal of Peace Research 45(2): I43-162.

Parameswaran, A. and P. R. Wijesinghe (20I2). "Was there a disparity in age appropriate infant immunization uptake in the theatre of war in the North of Sri Lanka at the height of the hostilities?: a cross-sectional study in resettled areas in the Kilinochchi district." BMC Int Health Hum Rights 12: 26.

Peace Direct. (20II). "Sudan: Conflict Profile." from http://www.insightonconflict.org/conflicts/sudan/ conflict-profile/ accessed on 2013, May I3.

Pickett, K. E., J. Mookherjee and R. G. Wilkinson (2005). "Adolescent birth rates, total homicides, and income inequality in rich countries." Am J Public Health 95(7): I I8I- I I83.

Pop, I. A., E. Ingen and W. Oorschot (2013). "Inequality, Wealth and Health: Is Decreasing Income Inequality the Key to Create Healthier Societies?" Social Indicators Research I I3(3): 1025-1043.

Rasella, D., R. Aquino and M. L. Barreto (20/3). "Impact of income inequality on life expectancy in a highly unequal developing country: the case of Brazil." Journal of Epidemiology and Community Health 67(8): 66I-666.

Rodgers, G. B. (1979). "Income and inequality as determinants of mortality: an international crosssection analysis." Population Studies 33: 343-35I.

Sen, A. (2000). Development as Freedom. New York, Knopf.

Sudan Central Bureau of Statistics (2010). Sudan National Baseline Household Survey 2009: North Sudan - Tabulation Report. Khartoum, Central Bureau of Statistics.

The Carter Center (undated). Report: Observing the 20II Referendum on the Self-Determination of Southern Sudan. 
http://www.cartercenter.org/resources/pdfs/new s/peace publications/election_reports/FinalRepor t-Sudan-20I I-Self-Determination-

Referendum.pdf accessed on 2013, May 13.

United Nations Human Development Program: Sudan. (20/2). "Status of MDGs in Sudan in 2012." from http://www.sd.undp.org/mdg_fact.htm accessed on 2013, May 13.

United Nations Missions (December 3I, 2004). The comprehensive Peace Agreement between the Government of the Republic of Sudan and the Sudan People's Liberation Army (SPLM/A). http://unmis.unmissions.org/Portals/UNMIS/Docu ments/General/cpa-en.pdf accessed on April 19, 2014.

Uthman, O. A. (2009). "Using extended concentration and achievement indices to study socioeconomic inequality in chronic childhood malnutrition: the case of Nigeria." Int J Equity Health 8: 22.

Van de Poel, E., A. R. Hosseinpoor, C. Jehu-Appiah, J. Vega and N. Speybroeck (2007). "Malnutrition and the disproportional burden on the poor: the case of Ghana." Int | Equity Health 6: 21.
Van de Poel, E., A. R. Hosseinpoor, N. Speybroeck, T. Van Ourti and J. Vega (2008). "Socioeconomic inequality in malnutrition in developing countries." Bull World Health Organ 86(4): 282291.

Wagstaff, A., E. van Doorslaer and N. Watanabe (2003). "On decomposing the causes of health sector inequalities with an application to malnutrition inequalities in Vietnam." Journal of Econometrics I I 2(I): 207-223.

Wilkinson, R. and K. E. Pickett (2009). The Spirit Level: why more equal societies almost always do better. London, Penguin.

Wilkinson, R. G. and K. E. Pickett (2006). "Income inequality and population health: a review and explanation of the evidence." Soc Sci Med 62(7): I768-I 784.

World Health Organization (1997). WHO Global Database on Child Growth and Malnutrition (page 50). Geneva, WHO.

You, D., J. R. New and T. Wardlaw (20I2). Levels \& Trends in Child Mortality, United Nations Interagency Group for Child Mortality Estimation. http://www.unicef.org/videoaudio/PDFs/UNICEF _2012_child_mortality_for_web_0904.pdf accessed on April 19, 2014.

Zere, E. and D. Mclntyre (2003). "Inequities in under-five child malnutrition in South Africa." Int Equity Health 2(I): 7. 